\title{
Erratum Notice of Formatting Correction In Vitro Cysteine Reactivates Organophosphate Insecticide Dichlorvos-Inhibited Human Cholinesterases
}

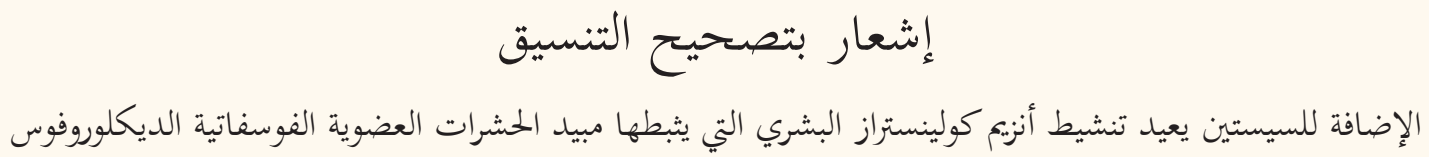

NOTICE OF ERRATUM FOR: MOHAMMADI ET AL. IN VITRO CYSTEINE REACTIVATES ORGANOPHOSPHATE INSECTICIDE DICHLORVOS-INHIBITED HUMAN CHOLINESTERASES. SULTAN QABOOS UNIV MED J 2017; 17:E293-300. DOI: 10.18295/SQUMJ.2017.17.03.006.

The Editors of Sultan Qaboos University Medical Journal (SQUMJ) have been informed of formatting errors in an article by Mohammadi et al. in the August 2017 issue of SQUMJ. ${ }^{1}$

The corresponding author, Seyed V. Shetab-Boushehri, contacted SQUMJ in October 2017 to inform the Editors of errors in the formatting of units of measurement throughout the article. The units of measurement had

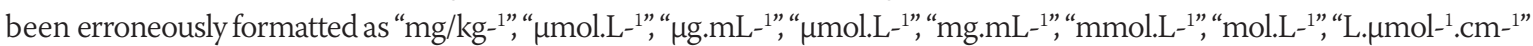

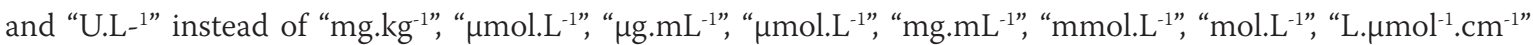
and "U.L.-", respectively. However, these corrections could not be made as the article had already been published the week previously. For the reasons stated herein, the Editors of SQUMJ wish to notify readers that the formatting of the aforementioned units of measurement should therefore be interpreted as the following: "mg.kg-1", " $\mu$ mol. $L^{-1}$ ",

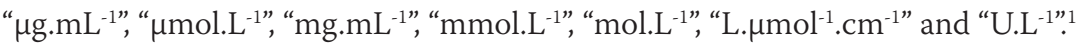

The Editors of SQUMJ take sole responsibility for this notice and would like to apologise to the authors and readers for this correction made after publication.

\section{References}

1. Mohammadi H, Jalilian J, Karimi MY, Shetab-Boushehri SV. In vitro cysteine reactivates organophosphate insecticide dichlorvos-inhibited human cholinesterases. Sultan Qaboos Univ Med J 2017; 17:e293-300. doi: 10.18295/squmj.2017.17.03.006. 